CLINICAL STUDY

\title{
Vitamin D status and parathyroid hormone in obese children before and after weight loss
}

\author{
Thomas Reinehr, Gideon de Sousa, Ute Alexy ${ }^{1}$, M Kersting $^{1}$ and Werner Andler \\ Vestische Hospital for Children and Adolescents Datteln, University of Witten/Herdecke, Dr F Steiner Strasse 5, 45711 Datteln, Germany and ${ }^{1}$ Research \\ Institute of Child Nutrition Dortmund, Institute at the Rheinische Friedrich-Wilhelms-University Bonn, Dortmund, Germany \\ (Correspondence should be addressed to T Reinehr; Email: t.reinehr@kinderklinik-datteln.de)
}

\begin{abstract}
Objective: The roles of vitamin D and parathyroid hormone (PTH) are discussed controversially in obesity, and studies of these hormones in obese children are limited. Therefore, we studied the relationships between PTH, 1,25-dihydroxy-vitamin D (1,25-OH Vit D), 25-hydroxy-vitamin D (25-OH Vit D), weight status, and insulin sensitivity before and after weight loss in obese children.

Methods: Fasting serum PTH, 1,25-OH Vit D, 25-OH Vit D, inorganic phosphate, calcium, alkaline phosphatase (AP), insulin, glucose, and weight status (SDS-BMI and percentage body fat) were determined in 133 obese children (median age 12.1 years) and compared with 23 non-obese children. Furthermore, these parameters were analyzed in 67 obese children before and after participating in a 1-year obesity intervention program.

Results: Obese children had significantly $(P<0.001)$ higher PTH and lower 25-OH Vit D concentrations compared with non-obese children, while calcium, phosphate, AP, and 1,25-OH Vit $\mathrm{D}$ did not differ significantly. Changes of PTH $(r=0.23, P=0.031)$ and $25-\mathrm{OH}$ Vit D $(r=-0.27$, $P=0.013)$ correlated significantly with changes of SDS-BMI, but not with changes of insulin sensitivity (homeostasis model assessment; HOMA-B\%). Reduction of overweight in 35 children led to a significant $(P<0.01)$ decrease of PTH concentrations and an increase in 25-OH Vit D levels. Conclusions: PTH levels were positively and 25-OH Vit D concentrations were negatively related to weight status. Since these alterations normalized after weight loss, these changes are consequences rather than causes of overweight. A relationship between PTH, vitamin D, and insulin sensitivity based on the HOMA index was not found in obese children. Further longitudinal clamp studies are neccessary to study the relationship between vitamin D and insulin sensitivity.
\end{abstract}

European Journal of Endocrinology 157 225-232

\section{Introduction}

Vitamin D and parathyroid hormone (PTH) are well known for their essential role in bone metabolism and calcium homeostasis. The main sources of vitamin D are ergocalciferol and cholecalciferol, the former normally available in food and the latter produced in the skin by u.v. radiation of 7-dehydrocholesterol. Both of these compounds are hydroxylated in the liver to 25-hydroxyvitamin D (25-OH Vit D), which is the major circulating metabolite precursor to the hormonally active form, 1,25-dihydroxy-vitamin D (1,25-OH Vit D).

It has become increasingly clear that the vitamin $\mathrm{D}$ endocrine system is related to obesity in adults. Obesity has been found to be associated with lower levels of serum 25-OH VitD (1-5) and higher levels of serum PTH (1, 5-8). A low vitamin D intake was associated with increased body mass index (BMI) (9). PTH has been postulated as an

This study is registered at clinicaltrials.gov (NCT00435734). independent predictor of obesity (7). Overweight as a consequence of elevated serum PTH was explained by several mechanisms $(10,11)$ : PTH stimulates the renal hydroxylation of 25-OH Vit D to its active form, 1,25-OH Vit D, which in turn elevates the calcium influx into adipocytes. In these cells, intracellular calcium enhances lipogenesis through the activation of fatty acid synthase and inhibits lipolysis via activation of phosphodiesterase $3 \mathrm{~B}$, which subsequently reduces catecholamine-induced lipolysis (11-13). Both these effects would promote lipid storage in fat tissue. Additionally, studies support a direct role for PTH in suppressing lipid oxidation in the muscle (14). However, these hypotheses are discussed controversially since in obese adults with weight loss, increasing and decreasing 25-OH Vit D as well as decreasing and increasing PTH concentrations have been reported (1520 ), so that the question whether the alterations of these hormones are a consequence or cause of overweight remains open.

Vitamin D also acts as a necessary cofactor for insulin secretion (21-24). Vitamin D repletion improves insulin 
sensitivity and insulin secretion in animal studies (25). Hypovitaminosis D has been proposed as a risk factor for reduced insulin secretion, impaired glucose tolerance, and type 2 diabetes in adults (23-29). However, some studies in obese adults demonstrated no relationship between vitamin D, PTH, and insulin sensitivity (30-32).

As data concerning the vitamin $\mathrm{D}$ endocrine system in obesity and its relation to insulin sensitivity are controversial, and studies in children are lacking, we studied PTH, 25-OH Vit D, 1,25-OH Vit D concentrations and their changes in obese children as well as their relationships to insulin sensitivity before and after participating in a 1-year obesity intervention program and compared them with normal weight children. The aims of this study were 1) to analyze the alterations of these hormones in obese children, 2) to prove their reversibility in weight loss pointing towards a consequence of overweight rather than a cause, and 3) to study the relationship between insulin sensitivity and vitamin D status.

\section{Methods}

We examined anthropometrical markers (weight, height, and skinfold thickness) as well as fasting serum PTH, 1,25-OH Vit D, 25-OH Vit D, calcium, inorganic phosphate alkaline phosphatase (AP), glucose, and insulin concentrations in 133 obese Caucasian children and in 23 healthy Caucasian normal weight children. Additionally, these parameters were determined in a subgroup of 67 obese children before and after participating in the same 1-year outpatient obesity intervention program. The 66 obese children who did not participate in the intervention had failed to prove their motivation by performing a 3-day dietary record, filling out a questionnaire concerning their eating and exercise habits, and participating regularly in an exercise therapy for overweight children for a period of 8 weeks (33). All analyses were performed in spring. Children with endocrine disorders, premature adrenarche, or syndromal obesity were excluded from the study. All participants were non-smokers without any regular medication. Obesity was defined according to International Task Force of Obesity (34).

Blood sampling was performed in the fasting state at 0800 h. 1,25-OH Vit D was determined by highly specific RIA (immunoextraction followed by quantification by ${ }^{125}$ I RIA, Gamma B 1,25-OH Vit D RIA Immunodiagnostic Systems, Boldon, UK) with crossreaction to $25-\mathrm{OH}$ Vit D of $0.001 \%$. The sensitivity of this assay was $3.4 \mathrm{pg} / \mathrm{ml}$. 25-OH Vit D was determined by a high-specific chemiluminescence-immunassay (LIAISON 25-OH-Vit D Assay, Diasorin, Dietzenbach, Germany) with cross-reaction to 1,25-OH Vit D of $1.1 \%$. The sensitivity of this assay was $2.0 \mathrm{ng} / \mathrm{ml}$. The normal range of this test kit for the 25-OH Vit D concentrations was $5-64 \mathrm{ng} / \mathrm{ml}$ (35). Intact PTH was determined by a highly specific solid-phase two-site chemiluminescent enzyme-labeled immunometric assay using an Immulite analyzer (DPC Biermann, Bad Nauheim, Germany). Insulin concentrations were measured by microparticleenhanced immunometric assay (Abbott). Glucose levels were determined by colorimetric test using a Vitros analyzer (Ortho Clinical Diagnostics, Neckargmuend, Germany). Calcium, Inorganic phosphate, and AP were measured by commercially available test kits (Calcium Cobas, Inorganic Phosphate Cobas, AP IFCC Cobas, Roche Diagnostics). Intra- and interassay coefficients of variation were $<14 \%$ for PTH, $25-\mathrm{OH}$ Vit D, and $1,25-\mathrm{OH}$ Vit $\mathrm{D}$ and $<5 \%$ for all other methods. Homeostasis model assessment (HOMA) was used to detect the degree of insulin resistance and insulin sensitivity (36); the resistance can be assessed from the fasting glucose and insulin concentrations by the formula: resistance $(\mathrm{HOMA}-\mathrm{IR})=($ fasting insulin $(\mathrm{mU} /$ I) $\times$ fasting glucose $(\mathrm{mmol} / \mathrm{I})) / 22.5$. Insulin sensitivity (HOMA-B\%) was computed as $(20 \times$ fasting insulin in $\mathrm{mU} / \mathrm{l}) /($ fasting glucose in $\mathrm{mmol} / \mathrm{l}-3.5$ ).

Height was measured to the nearest centimeter using a rigid stadiometer. Weight was measured unclothed to the nearest $0.1 \mathrm{~kg}$ using a calibrated balance scale. Since BMI is not normally distributed in childhood, we used the LMS method to calculate SDS-BMI as a measurement for the degree of overweight. This method summarizes the data in terms of three smooth age-specific curves termed $L(\lambda), M$ $(\mu)$, and $S(\sigma)$ based on German population-specific data $(37,38)$. The $M$ and $S$ curves correspond to the median and coefficient of variation body mass index for German children at each age and gender, whereas the $L$ curve allows for the substantial age-dependent skewness in the distribution of body mass index $(37,38)$. The assumption behind the LMS method is that after Box-Cox power transformation, the data at each age are distributed normally (37). Reduction of overweight was defined by a reduction in SDS-BMI, since BMI is age and gender dependent in childhood.

Tricep and subscapularis skinfold thickness was measured by one investigator in duplicate using a caliper and averaged to calculate the percentage of body fat, using a skinfold thickness equation with the following formulas (39):

$$
\begin{aligned}
& \text { Boys, body fat } \% \\
& =0.783 \times(\text { subscapularis skinfold thickness } \\
& \quad+\text { tricep skinfold thickness in } \mathrm{mm})+1.6
\end{aligned}
$$

Girls, body fat \%

$$
\begin{aligned}
= & 0.546 \times(\text { subscapularis skinfold thickness } \\
& + \text { tricep skinfold thickness in } \mathrm{mm})+9.7
\end{aligned}
$$

The pubic stage was determined by inspection and palpation according to Marshall and Tanner. Pubertal developmental stage was categorized into two groups 
(prepubertal: boys with pubic hair stage I and gonadal stage I, girls with pubic hair stage I and breast stage I; pubertal: boys with pubic hair stage $\geq$ II or gonadal stage $\geq$ II and girls with pubic hair stage $\geq$ II or breast stage $\geq$ II).

The 1-year obesity intervention program 'Obeldicks' has been described in detail elsewhere (33, 40, 41). Briefly, this outpatient intervention program for obese children is based on physical exercise, nutrition education, and behavior therapy including individual psychological care of the child and his or her family. The nutritional course is based on a fat- and sugar- reduced diet as compared with the everyday nutrition of German children; the diet contained $30 \mathrm{E} \%$ fat, $15 \mathrm{E} \%$ proteins, and $55 \mathrm{E} \%$ carbohydrates including $5 \mathrm{E} \%$ sugar. No diary products fortified with vitamin D were recommended.

For the assessment of dietary calcium and vitamin D intake, 3-day weighed dietary records were used. Children or their parents weighed and recorded all foods and fluids consumed as well as leftovers using electronic food scales $( \pm 1 \mathrm{~g})$ at baseline and at the end of intervention 1 year later. Semi-quantitative recording (e.g., number of spoons, scoops) was allowed if weighing was not possible. Dietary records were evaluated at the Research Institute of Child Nutrition. Energy and nutrient intakes were calculated using the nutrient database LEBTAB (42), which is continuously updated by all new recorded food items. For LEBTAB, nutrient contents of staple foods are taken from standard nutrient tables. Those of commercial food products are determined either by using the product labels or by simulating recipes from the ingredients listed, including fortification. Daily energy intake (kcal/day), daily vitamin $\mathrm{D}$ and calcium intake, and percentage energy (\%E) from fat, protein, and carbohydrates were calculated. To control for age effects, intake of macronutrients was expressed as percentage of energy intake (\%E).

Statistical analysis was performed using the WinSTAT software package (R Fitch Software, Bad-Krozingen, Germany). All variables were normally distributed as tested by Kolmogorov-Smirnov test. Student's $t$-tests for paired and unpaired observations were used. Correlations between PTH, vitamin D, weight status (SDS$\mathrm{BMI}$ ), insulin, and insulin resistance index (HOMA) at baseline were calculated by Pearson's correlation. Correlations between changes of these parameters after 1 year were calculated by Pearson's correlation and partial regression adjusted to changes of SDS-BMI. Changes were expressed as $\delta$-variable calculated by variable 1 year later - variable at baseline. Direct multivariate linear regression analyses were conducted for the dependent variables PTH, 1,25-OH Vit D, or 25-OH Vit D, including age, gender, pubertal stage, weight status (BMI), glucose, and insulin as independent variables. Gender and pubertal stage were used as classified variables in these models. A $P$ value $<0.05$ was considered significant. Data are presented as mean \pm s.D. Written informed consent was obtained from all children and their parents. The study was approved by the local ethics committee of the University of Witten/Herdecke.

\section{Results}

The anthropometrical data of the 133 obese and 23 normal weight children are presented in Table 1 . The 133 obese children demonstrated significantly increased PTH concentrations $(P<0.001)$ and decreased 25-OH Vit D levels compared to the 23 normal weight children, while the children did not differ in their 1,25-OH Vit D concentrations (Fig. 1). Four of the obese and none of the non-obese children demonstrated 25-OH Vit D levels below the normal range for German children. Furthermore, the obese and normal weight children did not differ in their calcium $(2.3 \pm 0.1$ vs $2.3 \pm 0.1 \mathrm{mmol} / \mathrm{l}, P=0.727)$, inorganic phosphate $(4.6 \pm 0.6$ vs $4.8 \pm 0.3 \mathrm{mg} / \mathrm{dl}, P=0.095)$, or AP levels $(212 \pm 87$ vs $212 \pm 51 \mathrm{U} / \mathrm{l}, \mathrm{P}=0.989)$.

At baseline, PTH correlated significantly positively to SDS-BMI $(r=0.25, P=0.008)$ and percentage body fat $(r=0.25, P=0.017)$, negatively to $25-\mathrm{OH}$ Vit $\mathrm{D}$ $(r=-0.23, P=0.004)$, but not significantly to $1,25-$ $\mathrm{OH}$ Vit D, age, insulin, HOMA-B\%, or HOMA-IR. 25-OH Vit D correlated significantly negatively to SDS-BMI $(r=-0.34, \quad P<0.001)$ and percentage body fat $(r=-0.33, P=0.005)$, but not significantly to 1,25-OH Vit D, age, insulin, HOMA-B\%, or HOMA-IR. $1,25-\mathrm{OH}$ Vit D correlated significantly to age $(r=0.18$, $P=0.013)$, but not significantly to SDS-BMI, percentage body fat, insulin, HOMA-B\%, or HOMA-IR. In multiple linear regression analyses adjusted for age, gender, pubertal stage and weight status (BMI), no significant correlation between insulin and PTH, 25-OH Vit D, and 1,25-OH Vit D could be observed.

The changes in weight status (SDS-BMI) of the 67 obese children between baseline and 1 year later correlated significantly to changes in PTH $(r=0.23$, $P=0.031)$ and $25-\mathrm{OH}$ Vit $\mathrm{D}(r=-0.27, P=0.013)$, but not significantly to changes in $1,25-\mathrm{OH}$ Vit D $(r=-0.03, P=0.389$; Fig. 2). Changes in insulin, HOMA-IR, and HOMA-B\% did not significantly correlate to the changes of PTH, 25-OH Vit D, and 1,25-OH Vit D in partial correlation adjusted for changes of weight status (SDS-BMI).

Table 1 Anthropometrical data of the obese and normal weight children.

\begin{tabular}{lllr}
\hline & Obese & Normal weight & P value \\
\hline Number & 133 & 23 & \\
Age (years) & $12.1 \pm 2.4$ & $11.9 \pm 1.9$ & 0.661 \\
Gender & $51 \%$ male & $52 \%$ male & 0.926 \\
Pubertal stage & $36 \%$ prepubertal & $35 \%$ prepubertal & 0.988 \\
BMI & $27.7 \pm 3.8$ & $17.3 \pm 3.0$ & $<0.001$ \\
SDS-BMI & $2.2 \pm 0.4$ & $-0.4 \pm 1.0$ & $<0.001$ \\
\hline
\end{tabular}



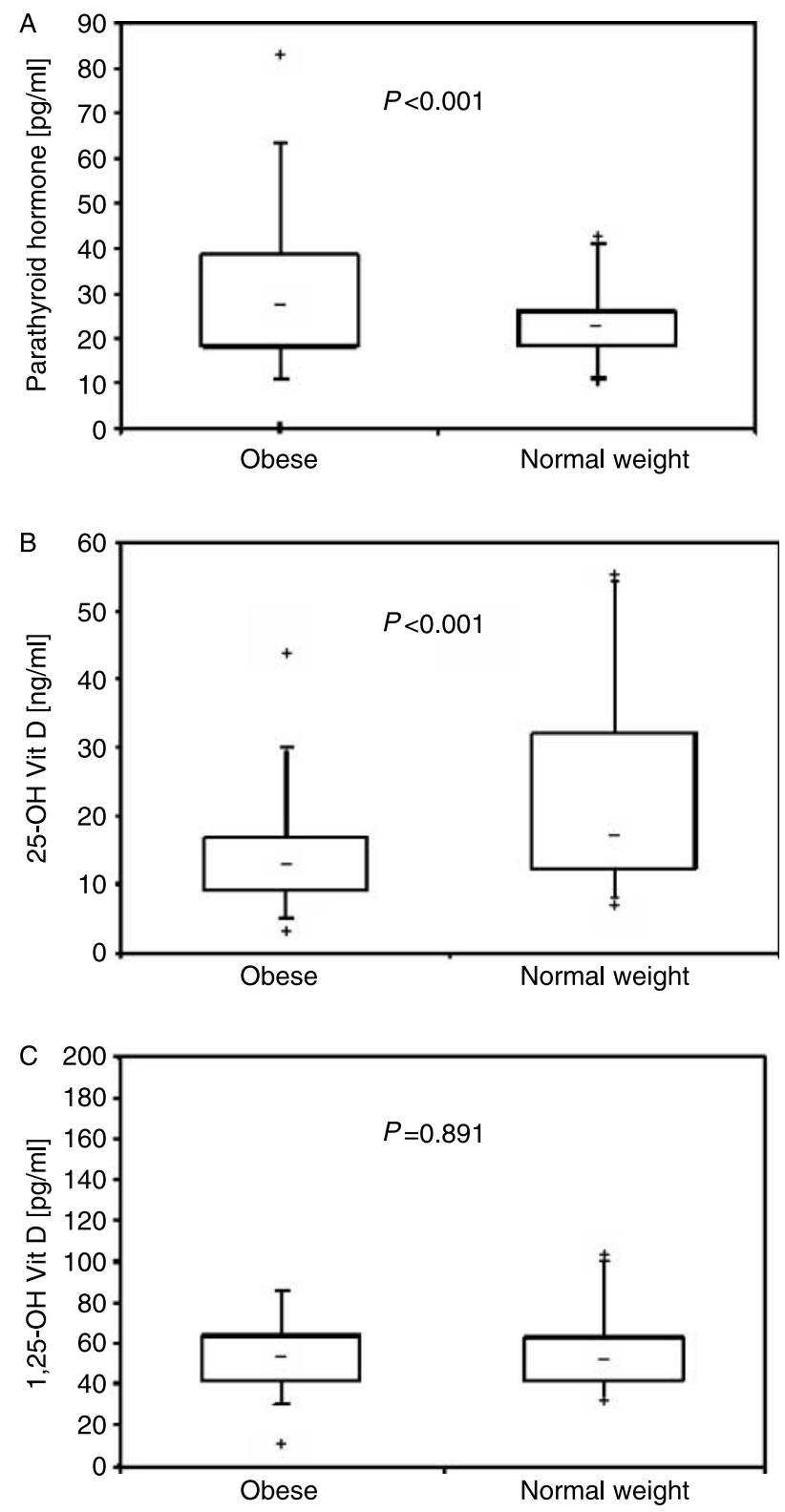

Figure 1 Parathyroid hormone (A), 25-hydroxy-vitamin $D(B)$, and 1,25-dihydroxy-vitamin $D(C)$ in 133 obese and 23 normal weight children.

The changes in HOMA-IR, HOMA-B $\%$, insulin, glucose, PTH, 25-Vit D, and 1,25-OH Vit D concentrations between baseline and 1 year later in the 35 obese children with reduction of overweight and the 32 obese children without reduction of overweight are shown in Table 2. The reduction of overweight led to a significant decrease of PTH levels and insulin resistance index (HOMA-IR), as well as an increase of $25-\mathrm{OH}$ Vit D concentrations, while 1,25-OH Vit D levels did not change significantly. In the obese children without reduction of overweight, no significant changes occurred apart from a significant increase of insulin
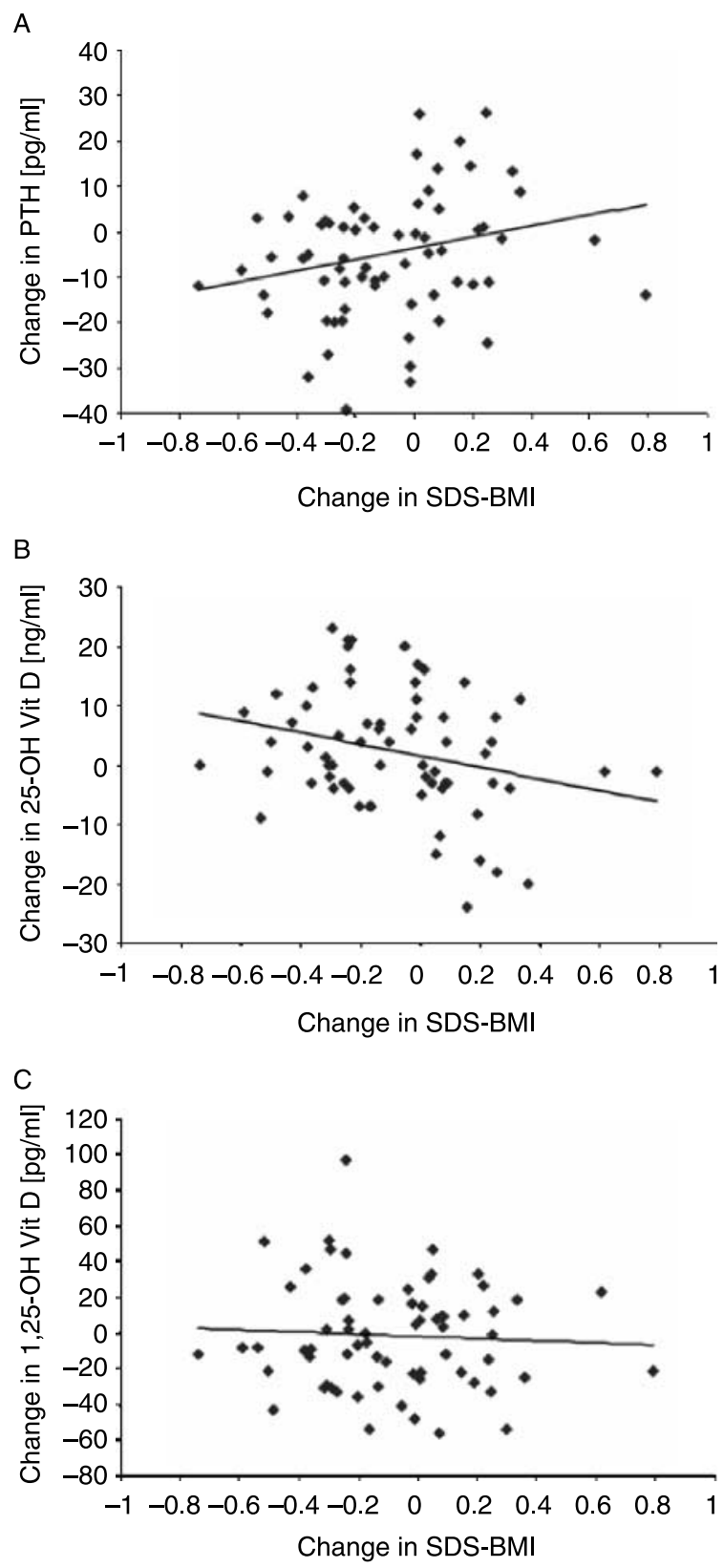

Figure 2 Changes in parathyroid hormone ((A), $r=0.23, P=0.031)$, 25-hydroxy-vitamin $\mathrm{D}((\mathrm{B}), r=-0.27, P=0.013)$ and

1,25 -dihydroxy-vitamin $\mathrm{D}((\mathrm{C}), r=-0.03, P=0.389)$ in relation to change of weight status (SDS-BMI) in the course of 1 year.

concentrations, insulin resistance index (HOMA-IR) and percentage body fat.

At baseline, no significant differences were observed in age, gender, pubertal stage, SDS-BMI, and percentage body fat between the obese children with and without weight loss (Table 2). Furthermore, there were no significant differences regarding PTH, 25-OH Vit D, or 1,25-OH Vit D levels between the obese children with and those without reduction of overweight. 
Table 2 Changes in weight status, percentage body fat, insulin resistance index (homeostasis model assessment; HOMA-IR), insulin sensitivity (HOMA-B\%), insulin, glucose, lipids, parathyroid hormone, 25-hydroxy-vitamin D (25-OH Vit D), and 1,25 OH- Vit D concentrations in 67 obese children with and without reduction of overweight over a 1 -year period.

\begin{tabular}{|c|c|c|c|c|}
\hline & \multicolumn{2}{|c|}{ Reduction of overweight } & \multicolumn{2}{|c|}{ No reduction of overweight } \\
\hline \multirow{6}{*}{$\begin{array}{l}\text { Number } \\
\text { Age (years) } \\
\text { Gender } \\
\text { Pubertal stage } \\
\text { Change of SDS-BMI }\end{array}$} & \multirow{5}{*}{\multicolumn{2}{|c|}{$\begin{array}{c}35 \\
11.1 \pm 2.3 \\
51 \% \text { male } \\
46 \% \text { prepubertal } \\
-0.3 \pm 0.1\end{array}$}} & \multirow{5}{*}{\multicolumn{2}{|c|}{$\begin{array}{c}32 \\
11.0 \pm 2.5 \\
59 \% \text { male } \\
43 \% \text { prepubertal } \\
+0.1 \pm 0.2\end{array}$}} \\
\hline & & & & \\
\hline & & & & \\
\hline & & & & \\
\hline & & & & \\
\hline & At baseline & 1 year later & At baseline & 1 year later \\
\hline BMI $\left(\mathrm{kg} / \mathrm{m}^{2}\right)$ & $27.3 \pm 3.5$ & $26.4 \pm 3.0^{\dagger}$ & $26.5 \pm 4.4$ & $28.1 \pm 3.7^{\dagger}$ \\
\hline SDS-BMI & $2.3 \pm 0.4$ & $2.0 \pm 0.3^{\dagger}$ & $2.2 \pm 0.3$ & $2.3 \pm 0.4^{\dagger}$ \\
\hline Subscapularis ST (mm) & $30 \pm 7$ & $26 \pm 7^{\dagger}$ & $29 \pm 12$ & $31 \pm 5$ \\
\hline Triceps ST $(\mathrm{mm})$ & $31 \pm 6$ & $26 \pm 8^{\dagger}$ & $29 \pm 11$ & $31 \pm 6$ \\
\hline Percentage body fat (\%) & $46 \pm 12$ & $40 \pm 11^{\dagger}$ & $45 \pm 19$ & $48 \pm 7^{*}$ \\
\hline Insulin (mU/I) & $19 \pm 14$ & $13 \pm 7^{*}$ & $17 \pm 9$ & $21 \pm 10^{*}$ \\
\hline Glucose (mg/dl) & $88 \pm 4$ & $86 \pm 6$ & $87 \pm 6$ & $88 \pm 7$ \\
\hline HOMA-B\% & $226 \pm 121$ & $286 \pm 108$ & $230 \pm 136$ & $282 \pm 166$ \\
\hline HOMA-IR & $4.0 \pm 2.9$ & $2.8 \pm 1.4^{*}$ & $3.6 \pm 2.1$ & $4.4 \pm 2.5^{\star}$ \\
\hline PTH $(\mathrm{pg} / \mathrm{ml})$ & $29 \pm 9$ & $20 \pm 6^{\dagger}$ & $29 \pm 11$ & $29 \pm 12$ \\
\hline 1,25-OH Vit D (pg/ml) & $56+14$ & $55+9$ & $55+18$ & $57 \pm 16$ \\
\hline $25-\mathrm{OH}$ Vit D $(\mathrm{ng} / \mathrm{ml})$ & $11 \pm 4$ & $16 \pm 9^{\dagger}$ & $13 \pm 8$ & $12 \pm 7$ \\
\hline Calcium (mmol/l) & $2.3 \pm 0.1$ & $2.3 \pm 0.1$ & $2.3 \pm 0.1$ & $2.3 \pm 0.1$ \\
\hline Inorganic phosphate $(\mathrm{mg} / \mathrm{dl})$ & $4.8 \pm 0.5$ & $4.7 \pm 0.3$ & $4.7 \pm 0.4$ & $4.5 \pm 0.6$ \\
\hline Alkaline phosphatase (U/l) & $194 \pm 49$ & $194 \pm 21$ & $190 \pm 63$ & $202 \pm 75$ \\
\hline
\end{tabular}

Data as median and interquartile range.

${ }^{\star} P<0.05$ baseline versus 1 year later; ${ }^{\dagger} P<0.01$ baseline versus 1 year later; ST, skinfold thickness.

Fourteen $(40 \%)$ children with reduction of overweight and $20(63 \%)$ children without reduction of overweight did not perform a 3-day dietary record after the end of intervention. These children did not differ significantly from the children with complete dietary records with respect to age, gender, and degree of overweight at baseline. Furthermore, the children with or without complete dietary records did not differ significantly in their PTH, 25-OH Vit D, or 1,25-OH Vit D concentrations. In the children with complete dietary records, caloric intake and percentage fat content in diet decreased significantly, while percentage carbohydrate content in diet increased significantly regardless of weight loss (see Table 3). Calcium intake did not change significantly in the children with or without weight loss. Vitamin D intake decreased in the children without reduction of overweight, while vitamin D intake remained stable $(P=0.244)$ in the children with reduction of overweight. At baseline, there were no significant differences in diet composition with respect to fat, carbohydrate and protein content, as well as in caloric, vitamin $\mathrm{D}$, and calcium intake between the children with and without overweight reduction.

\section{Discussion}

This is the first study analyzing cross-sectional and longitudinal relationships between the vitamin D endocrine system, weight status, and insulin sensitivity in childhood. We were able to demonstrate that obese children had significantly higher PTH levels and lower 25-OH Vit D concentrations as compared with non-obese children. PTH levels decreased and 25-OH Vit D concentrations increased significantly in obese children, who achieved a reduction of overweight in the course of 1 year in contrast to obese children without reduction of overweight. Therefore, the alterations of these hormones are a consequence rather than a cause of overweight.

The low levels of 25-OH Vit D in obese children in our study are in concordance with most studies in adults (1-5, 15, 43). A good vitamin D status has been postulated to prevent obesity $(11,27,29,44)$. Since 25-OH Vit D concentrations increased after reduction of overweight, this finding points towards a consequence rather than a cause of overweight. Since the main source of vitamin D in Germany is alimentary intake due to the geographical latitude, a change of vitamin D intake during the intervention may have caused the increase of 25-OH Vit D concentrations. However, the 3-day weighed dietary records did not demonstrate an increase in vitamin D consumption. The higher vitamin D levels in normal weight subjects seem to be more a surrogate parameter for healthy nutrition than a real causal factor in the prevention of obesity. Intervention studies in obese children with vitamin D supplementation are necessary to prove this hypothesis. Furthermore, the low levels of 25-OH Vit D may be attributed to several other factors such as decreased exposure to sunlight in obese subjects due to limited 
Table 3 Energy intake (kcal/day), calcium and vitamin D intake ( $\mu \mathrm{g} / \mathrm{day})$, as well as composition (\%E fat, \%E carbohydrate, and \%E protein) in 3-day weighed dietary records at baseline and 1 year later in children with and without reduction of overweight.

\begin{tabular}{|c|c|c|c|c|}
\hline & \multicolumn{2}{|c|}{ Reduction of overweight $(n=21)$} & \multicolumn{2}{|c|}{ No reduction of overweight $(n=12)$} \\
\hline & At baseline & 1 year later & At baseline & 1 year later \\
\hline Energy intake (kcal/day) & $1448 \pm 350$ & $1186 \pm 267^{\dagger}$ & $1475 \pm 432$ & $1220 \pm 357^{*}$ \\
\hline Fat (E\%) & $35.3 \pm 4.9$ & $29.3 \pm 8.4^{\dagger}$ & $36.4 \pm 4.6$ & $32.0 \pm 3.9^{\star}$ \\
\hline Carbohydrate (E\%) & $49.3 \pm 4.9$ & $52.9 \pm 7.8^{*}$ & $47.7 \pm 5.2$ & $51.8 \pm 4.1^{*}$ \\
\hline Protein $(\mathrm{E} \%)$ & $15.4 \pm 1.7$ & $17.7 \pm 2.2^{\dagger}$ & $15.9 \pm 2.8$ & $16.1 \pm 1.7$ \\
\hline Vitamin $D$ intake ( $\mu \mathrm{g} /$ day) & $0.976 \pm 0.621$ & $0.809 \pm 424$ & $1.007 \pm 0.390$ & $0.658 \pm 0.288^{*}$ \\
\hline Calcium intake (mg/day) & $653 \pm 232$ & $656 \pm 205$ & $710 \pm 316$ & $744 \pm 316$ \\
\hline
\end{tabular}

Data as median and interquartile range.

${ }^{\star} P<0.05$ baseline versus 1 year later; ${ }^{\dagger} P<0.01$ baseline versus 1 year later.

mobility, clothing habits, or the excessive deposition of vitamin $\mathrm{D}$ in adipose tissue $(1,3,4)$. The increase in serum $25-\mathrm{OH}$ Vit D after sun exposure was $57 \%$ less in obese compared with non-obese subjects (45). Additionally, adipose tissue is a major storage site of vitamin $\mathrm{D}$ (46).

Even if obese children had 25-OH Vit D concentrations in mean below the 25-OH Vit D concentrations of healthy non-obese children and even if four obese children had 25-OH Vit D levels below the normal range, the clinical relevance of these findings is at least questionable. We found no alterations in calcium, inorganic phosphate, AP, and most importantly in 1,25-OH Vit D levels, the bioactive vitamin D metabolite.

PTH concentrations were elevated in obese children in our study in concordance with most studies in adults $(1,3-5,7,43)$. Since patients with primary or secondary hyperparathyroidism were heavier than those in the control group, it has been postulated that increased PTH levels contribute towards obesity $(6,47,48)$. Conversely, PTH decreased after weight loss in our study in concordance with most studies in obese adults $(19,20,49)$, suggesting that the elevated serum PTH is a result and not a cause of obesity. Furthermore, we observed no alteration of 1,25-OH Vit D levels in our study of obese children. 1,25-OH Vit D has been postulated to mediate the effect of PTH on intracellular calcium influx as a mechanism for increased fat storage $(10,11)$.

The conflicting findings of increasing 25-OH Vit D and decreasing PTH in comparison with studies in obese adults with weight loss could be explained by the fact that weight loss was achieved in these studies by gastric surgery $(17,18)$. It is well known that, for example, Roux-Y bypass is associated with alterations in the vitamin D endocrine system such as secondary hyperparathyroidism due to disturbed resorption of vitamin D $(16,18)$.

One further finding of the present study is that $25-\mathrm{OH}$ Vit D and PTH serum levels were not a major determinant of insulin sensitivity in obese children in cross-sectional and, most importantly, in longitudinal analysis. This finding is in concordance with most studies in obese adults $(21,32,50)$. The association between low circulating concentrations of vitamin D, high PTH levels, and the prevalence of diabetes and impaired glucose tolerance in adults was mainly derived from cross-sectional studies $(23,24,26,51)$, which are susceptible to confounder effects. Apart from a lack of power due to the moderate study sample size, the normal 1,25-OH Vit D concentrations in our obese children could explain the missing relation between Vit $\mathrm{D}$ and insulin sensitivity, since 1,25-OH Vit D is essential for normal insulin secretion (51). Moreover, the HOMA model is only an assessment of insulin resistance and $\beta$-cell function. Clamp studies are the gold standard to analyze insulin resistance and sensitivity (52). Since the HOMA model correlates to clamp studies, it is a suitable method to study insulin resistance in field studies (53, 54). However, it has been reported that in vitamin D-depleted subjects especially the late insulin secretion is altered (23), which cannot be calculated by the HOMA model. Therefore, a relationship between insulin sensitivity and vitamin D status cannot be excluded by our study.

This study has a few further potential limitations. First, BMI percentiles and skinfold measurements were used to classify overweight. Although BMI and skinfold measurements are good measures for overweight, one needs to be aware of their limitations as an indirect measure of fat mass. Secondly, we cannot distinguish the effect of diet and increased physical activity on change of vitamin D status and change of PTH, since both occurred in parallel in our intervention program as described previously $(55,56)$. However, a change in vitamin $\mathrm{D}$ or calcium intake was not observed in children with substantial overweight reduction in concordance with previous studies of this type of intervention (55). The tendency for lower vitamin D intake after intervention may be explained by the increased consumption of fat-reduced milk (55). Thirdly, dietary records were used for analyzing diet composition. Underreporting is a well-known phenomenon in obese subjects (57). Since in the obese children without overweight reduction, the recorded energy intake decreased, this finding suggests underreporting. Therefore, these dietary records have to be interpreted very 
cautiously and underreporting might also explain the lower vitamin D intake after intervention. Furthermore, dietary recording after the end of intervention was performed only in a subgroup of our study sample representing a potentially important bias. Finally, we have only demonstrated a statistical association between serum vitamin D system and weight status, which does not necessarily imply a cause-and-effect relationship. Accordingly, these alterations may simply be a pathophysiologically unrelated marker of obesity or related to other factors influencing both weight status and the vitamin D endocrine system. For instance, a deranged renal handling of calcium has been reported in obesity leading to a negative calcium balance and thus elevated serum PTH levels (20). This increased excretion of calcium was in parallel with sodium excretion (58), and the elevation of the latter may be a result of a higher salt intake in obese subjects (59).

In summary, fasting PTH levels were increased and 25-OH Vit D concentrations were decreased in obese children. These alterations normalized after reduction of overweight pointing towards reversibility in weight loss. PTH, 1,25-OH Vit D, and 25-OH Vit D were not related to insulin sensitivity in both cross-sectional and longitudinal analyses. Further prospective research is required to determine the physiological role of vitamin D endocrine system in obese humans.

\section{Acknowledgements}

We thank Mrs P Niklowitz, Children's Hospital Datteln University of Witten/Herdecke for her kind support in the laboratory.

\section{References}

1 Bell NH, Epstein S, Greene A, Shary J, Oexmann MJ \& Shaw S. Evidence for alteration of the vitamin D-endocrine system in obese subjects. Journal of Clinical Investigation 198576 370-373.

2 Buffington C, Walker B, Cowan GS, Jr \& Scruggs D. Vitamin D deficiency in morbidly obese. Obesity Surgery 19933 421-424.

3 Arunabh S, Pollack S, Yeh J \& Aloia JF. Body fat content and 25-hydroxyvitamin D levels in healthy women. Journal of Clinical Endocrinology and Metabolism 200388 157-161.

4 Worstman J, Matsuoka LY, Chen TC, Lu Z \& Holick MF. Decreased bioavailability of vitamin D in obesity. American Journal of Clinical Nutrition 200072 690-693.

5 Parikh SJ, Edelman M, Uwaifo GI, Freedman RJ, Semega-Janneh M, Reynolds J \& Yanovski JA. The relationship between obesity and serum 1,25- dihydroxyvitamin D concentrations in healthy adults. Journal of Clinical Endocrinology and Metabolism $2004 \mathbf{8 9}$ 1196-1199.

6 Stein MS, Flicker L, Scherer SC, Paton LM, O'Brien ML, Walton SC, Chick P, Di Carlantonio M, Zajac JD \& Wark JD. Relationships with serum parathyroid hormone in old institutionalized subjects. Clinical Endocrinology 200154 583-592.

7 Kamycheva E, Sundsfjord J \& Jorde R. Serum parathyroid hormone level is associated with body mass index. The 5th Tromsø Study. European Journal of Endocrinology 2004151 167-172.
8 Gunther CW, Legowski PA, Lyle RM, Weaver CM, McCabe LD, McCabe GP, Peacock M \& Teegarden D. Parathyroid hormone is associated with decreased fat mass in young healthy women. International Journal of Obesity 200630 94-99.

9 Kamycheva E, Joakimsen RM \& Jorde R. Intakes of calcium and vitamin D predict body mass index in the population of Northern Norway. Journal of Nutrition 2002132 102-106.

10 Portale AA \& Miller WL. Human 25-hydroxylation D-1ahydroxylase: cloning, mutations, and gene expression. Pediatric Nephrology 200014 620-625.

11 Zemel MB, Shi H, Greer B, Dirienzo D \& Zemel PC. Regulation of adiposity by dietary calcium. FASEB Journal 200014 1132-1138.

12 McCarty MF \& Thomas CA. PTH excess may promote weight gain by impeding catecholamine-induced lipolysis -implications for the impact of calcium, vitamin D, and alcohol on body weight. Medical Hypotheses $200361535-542$.

13 Shi H, Dirienzo D \& Zemel MB. Effects of dietary calcium on adipocyte lipid metabolism and body weight regulation in energyrestricted aP2-agouti transgenic mice. FASEB Journal 200115 291-293.

14 Smogorzewski M, Perna AF, Borum PR \& Massry SG. Fatty acid oxidation in the myocardium: effects of parathyroid hormone and CRF. Kidney International 198834 797-803.

15 Teitelbaum SL, Halverson JD, Bates M, Wise L \& Haddad JG. Abnormalities of circulating 25-OH vitamin D after jejunal bypass for obesity: evidence of an adaptive response. Annals of Internal Medicine 197786 289-293.

16 Rickers H, Christiansen C, Balsev I \& Rodbro P. Impairment of vitamin D metabolism and bone mineral content after intestinal bypass surgery. Scandinavian Journal of Gasteroenterology 198419 184-189.

17 Newbury L, Dolan K, Hatzifptis M, Low N \& Fielding G. Calcium and vitamin D depletion and elevated parathyroid hormone following biliopancreatic diversion. Obesity Surgery 200313 893-895.

18 Slater GH, Ren CJ, Siegel N, Williams T, Barr D, Wolfe B, Dolan K \& Fielding GA. Serum fat-soluble vitamin deficiency and abnormal calcium metabolism after malabsorptive bariatric surgery. Journal of Gastrointestinal Surgery $2004 \mathbf{8} 48-55$.

19 Jensen LB, Kollerup G, Quaade F \& Sorensen OH. Bone minerals changes in obese women during a moderate weight loss with and without calcium supplementation. Journal of Bone and Mineral Research 200116 141-147.

20 Andersen T, McNair P, Hyldstrup L, Fogh-Andersen N, Nielsen TT, Astrup A \& Transbøl I. Secondary hyperparathyroidism of morbid obesity regresses during weight reduction. Metabolism 198837 425-428.

21 Manco M, Calvani M, Nanni G, Greco AV, Iaconelli A, Gasbarrini G, Castagneto M \& Mingrone G. Low 25-hydroxyvitamin D does not affect insulin sensitivity in obesity after bariatric surgery. Obesity Research 200513 1692-1700.

22 Holick MF. Vitamin D: importance in the prevention of cancers, type 1 diabetes, heart disease, and osteoporosis. American Journal of Clinical Nutrition 200479 362-371.

23 Chiu KC, Chu A, Go VL \& Saad MF. Hypovitaminosis D is associated with insulin resistance and beta cell dysfunction. American Journal of Clinical Nutrition 200479 820-825.

24 Baynes KC, Boucher BJ, Feskens EJ \& Kromhout D. Vitamin D, glucose tolerance and insulinaemia in elderly men. Diabetologia 199740 344-347.

25 Cade C \& Norman AW. Vitamin D3 improves impaired glucose tolerance and insulin secretion in the vitamin D-deficient rat in vivo. Endocrinology $198611984-90$.

26 Boucher BJ, Mannan N, Noonan K, Hales CN \& Evans SJ. Glucose intolerance and impairment of insulin secretion in relation to vitamin D deficiency in east London Asians. Diabetologia 199538 1239-1245.

27 Isaia G, Giorgino R \& Adami S. High prevalence of hypovitaminosis D in female type 2 diabetic population. Diabetes Care 2001241496. 
28 Norman AW, Frankel JB, Heldt AM \& Grodsky GM. Vitamin D deficiency inhibits pancreatic secretion of insulin. Science 1980 209 823-825.

29 Scragg R, Sowers M \& Bell C. Serum 25- hydroxyvitamin D, diabetes, and ethnicity in the Third National Health and Nutrition Examination Survey. Diabetes Care 200427 2813-2818.

30 Mak RH, Bettinelli A, Turner C, Haycock GB \& Chantler C. The influence of hyperparathyroidism on glucose metabolism in uremia. Journal of Clinical Endocrinology and Metabolism $1985 \mathbf{6 0}$ 229-233.

31 Fliser D, Stefanski A, Franek E, Fode P, Gudarzi A \& Ritz E. No effect of calcitriol on insulin-mediated glucose uptake in healthy subjects. European Journal of Clinical Investigation 1997 27 629-633.

32 Panidis D, Balaris C, Farmakiotis D, Rousso D, Kourtis A, Balaris V, Katsikis I, Zournatzi $V$ \& Diamanti-Kandarakis E. Serum parathyroid hormone concentrations are increased in women with polycystic ovary syndrome. Clinical Chemistry $2005 \mathbf{5 1}$ 1691-1697.

33 Reinehr T, Brylak K, Alexy U, Kersting M \& Andler W. Predictors to success in outpatient training in obese children and adolescents. International Journal of Obesity $2003 \mathbf{8 9} 419-422$.

34 Cole TJ, Bellizzi MC, Flegal KM \& Dietz WH. Establishing a standard definition for child overweight and obesity worldwide: international survey. BMJ 2000320 1240-1243.

35 Kruse K. Kalzium-phosphat-stoffwechselströungen. In Pädiatrische Endokrinologie, edn 2, pp S-111-S-159. Ed. K Kruse, ThiemeVerlag: Stuttgart, 1999.

36 Matthews DR, Hosker JP, Rudenski AS, Naylor BA, Treacher DF \& Turner RC. Homeostasis model assessment: insulin resistance and beta-cell function from fasting plasma glucose and insulin concentrations in man. Diabetologia 198528 412-419.

37 Cole TJ. The LMS method for constructing normalized growth standards. European Journal of Clinical Nutrition 1990 44 45-60.

38 Kromeyer-Hauschild K, Wabitsch M, Kunze D, Geller F, Geiß HC, Hesse V, von Hippel A, Jaeger U, Johnsen D, Korte W, Menner K, Müller G, Müller M, Niemann-Pilatus A, Remer T, Schaefer F, Wittchen HU, Zabransky S, Zellner K, Ziegler A \& Hebebrand J. Percentiles of body mass index in children and adolescents evaluated from different regional German Studies. Monatsschrift Kinderheilkunde 2001149 807-818.

39 Slaughter MH, Lohman TG, Boileau RA, Horswill CA, Stillman RJ, Van Loan MD \& Bemben DA. Skinfold equations for estimation of body fatness in children and youth. Human Biology $1988 \mathbf{6 0}$ 709-723.

40 Reinehr T, de Sousa G, Toschke M \& Andler W. Long-term followup of cardiovascular disease risk factors in obese children after intervention. American Journal of Clinical Nutrition $2006 \mathbf{8 4}$ 490-496.

41 Reinehr T, Kersting M, Alexy U \& Andler W. Long-term follow-up of overweight children: after training, after a single consultation session and without treatment. Journal of Pediatric Gastroenterology and Nutrition 200337 72-74.

42 Sichert-Hellert W, Kersting M, Chahda C, Schäfer R \& Kroke A. German food composition database for dietary evaluations in children and adolescents. Journal of Food Composition and Analysis 20071 63-70.

43 Snijder MB, van Dam RM, Visser M, Deeg DJH, Dekker MJ, Bouter LM, Seidell JC \& Lips P. Adiposity in relation to vitamin D status and parathyroid hormone levels: a Population-Based Study in Older Men and Women. Journal of Clinical Endocrinology and Metabolism 200590 4119-4123.

44 Zemel MB. Mechanisms of dairy modulation of adiposity. Journal of Nutrition 2003133 252-256.
45 Need AG, Morris HA, Horowitz M \& Nordin C. Effects of skin thickness, age, body fat, and sunlight on serum 25- hydroxyvitamin D. American Journal of Clinical Nutrition $1993 \mathbf{5 8} 882-885$.

46 Mawer EB, Backhouse J, Holman CA, Lumb GA \& Stanbury SW. The distribution and storage of vitamin $\mathrm{D}$ and its metabolites in human tissues. Clinical Science $1972 \mathbf{4 3} 414-431$.

47 Bolland MJ, Grey AB, Gamble GD \& Reid IR. Association between primary hyperparathyroidism and increased body weight: a metaanalysis. Journal of Clinical Endocrinology and Metabolism 200590 1525-1530.

48 Grey AB, Evans MC, Stapleton JP \& Reid IR. Body weight and bone mineral density in postmenopausal women and primary hyperparathyroidism. Annals of Internal Medicine 1994121 745-749.

49 Pugnale N, Giusti V, Suter M, Zysset E, Heraief E, Gaillard RC \& Burckhardt P. Bone metabolism and risk of secondary hyperparathyroidism 12 months after gastric banding in obese premenopausal women. International Journal of Obesity and Related Metabolic Disorders 200327 110-116.

50 Liu S, Song Y, Ford ES, Manson JE, Buring JE \& Ridker P. Dietary calcium, vitamin D, and the prevalence of metabolic syndrome in middle-aged and older US women. Diabetes Care $2005 \mathbf{2 8}$ 2926-2932.

51 Scragg R, Holdaway I, Singh V, Metcalf P, Baker J \& Dryson E. Serum 25-hydroxyvitamin D3 levels decreased in impaired glucose tolerance and diabetes mellitus. Diabetes Research and Clinical Practice 199527 181-188.

52 Ten S \& Maclaren N. Insulin resistance syndrome in children. Journal of Clinical Endocrinology and Metabolism 2004 89 2526-2539.

53 Wallace TM \& Matthews DR. The assessment of insulin resistance in man. Diabetic Medicine $200219527-534$.

54 Haffner SM, Gonzalez C, Miettinewn H, Kennedy E \& Stern S. A prospective analysis of the HOMA model. Diabetes care 199619 1138-1141.

55 Alexy U, Reinehr T, Sichert-Hellert W, Wollenhaupt A, Kersting $M$ \& Andler W. Effects of an outpatient training program for overweight children on dietary habits - comparison with an untreated control group. Nutrition Research $2006 \mathbf{2 6}$ 202-208.

56 Reinehr T, Kersting M, Wollenhaupt A, Alexy U, Kling B, Ströbele K \& Andler W. Evaluation of the training program 'OBELDICKS' for obese children and adolescents. Klinische Padiatrie 2005217 1-8.

57 McGowan MJ, Harrington KE, Kiely M, Robson PJ, Livingstone MB \& Gibney MJ. An evaluation of energy intakes and the ratio of energy intake to estimated basal metabolic rate (EI/BMRest) in the North/South Ireland Food Consumption Survey. Public Health Nutrition 2001 4 1043-1050.

58 Carbone LD, Bush AJ, Barrow KD \& Kang AH. The relationship of sodium intake to calcium and sodium excretion and bone mineral density of the hip in postmenopausal African-American and caucasian women. Journal of Bone and Mineral Metabolism 2003 21 415-420.

59 Elliott P, Rogers S, Scally G, Beevers DG, Lichtenstein MJ, Keenan G, Hornby R, Evans A, Shipley MJ \& Elwood PC. Sodium, potassium, body mass, alcohol and blood pressure in three United Kingdom centres (the INTERSALT Study). European Journal of Clinical Nutrition $1990 \mathbf{4 4} 637-645$.

Received 22 March 2007

Accepted 23 May 2007 